\title{
METAMORFISMO DE CONTATO NO COMPLEXO BOSSOROCA, PORÇÃO SW DO COMPLEXO GRANÍTICO SÃO SEPÉ, RS
}

\author{
IRANI CLEZAR MATTOS ${ }^{1}$, RUY PAULO PHILIPP ${ }^{2}$, ANDRÉ SAMPAIO MEXIAS ${ }^{2} \&$ \\ MARCIA ELISA BOSCATO GOMES ${ }^{2}$
}

\begin{abstract}
CONTACT METAMORPHISM IN THE BOSSOROCA COMPLEX, SOUTHWESTERN PORTION OF THE SÃO SEPÉ GRANITIC COMPLEX, RS The São Sepé Granitic Complex (SSGC) is an NE-SW elongate body that intruded low-grade metamorphic rocks of the Bossoroca Complex. The emplacement of the granite in high crustal levels resulted on an aureole of contact metamorphism with 1,5 to 5 kilometers of extension. The thermal effects are registered mainly in metapelitics and metavolcanoclastic rocks of the Bossoroca Complex, and the biotite, garnet, andaluzite and staurolite isograds were mapped. The contact metamorphism extended until the sediments of the Maricá Group of the Camaquã Basin. The cooling of the magma of SSGC is a continuous process characterized by two different stages: the transfer of heat for conduction, resulting on the contact metamorphism, followed by the infiltration of tardi-magmatics fluids with generation of the hydrothermal assemblage. Petrographic and thermo barometric data indicates that the emplacement and the cooling of SSGC happened in little depth, with pressures of the order of the 2,5 to 4,5 kbares and maximum temperatures in the interval among $570^{\circ}$ to $600^{\circ} \mathrm{C}$. The effects of the contact metamorphism also recorded in the sediments of the Maricá Group suggesting that the intrusion of the granite follows the sedimentation of the basal units of the Camaquã Basin.
\end{abstract}

Keywords: Sul-rio-grandense Shield, contact metamorphism, granitic rocks, petrology

\begin{abstract}
Resumo O Complexo Granítico São Sepé (CGSS) constitui um maciço com forma ligeiramente alongada segundo a direção NE-SW, intrusivo nas rochas metamórficas do Complexo Bossoroca. O posicionamento do granito em níveis crustais elevados ocasionou a formação de uma auréola de metamorfismo de contato com cerca de 1,5 a 4 quilômetros de extensão. Os efeitos termais estão registrados principalmente nas rochas metapelíticas e metavulcanoclásticas do Complexo Bossoroca, entretanto, estendem-se até os sedimentos do Grupo Maricá da Bacia do Camaquã. Nos metapelitos é possível demarcar em campo, as isógradas da biotita, granada, andaluzita e estaurolita, dispostas respectivamente, da zona mais afastada até as mais próximas do contato. O resfriamento do magma do CGSS é um processo contínuo caracterizado por duas etapas distintas: transferência de calor por condução, gerando o metamorfismo de contato, e infiltração de fluidos tardi-magmáticos, com geração de paragêneses hidrotermais. A reunião dos dados petrográficos, químico-mineralógicos e termométricos indica que a colocação e o resfriamento do CGSS ocorreu em pouca profundidade, com pressões da ordem dos 2,5 a 4,5 kbares e temperaturas máximas no intervalo entre $570^{\circ}$ a $600^{\circ} \mathrm{C}$. O registro de metamorfismo de contato também nas litologias sedimentares do Grupo Maricá é indicativo que o posicionamento do CGSS é posterior a sedimentação da porção basal da Bacia do Camaquã.
\end{abstract}

Palavras-chave: Escudo Sul-rio-grandense, metamorfismo de contato, granitóides, petrogênese

INTRODUÇÃO A transferência termal associada à intrusão de corpos graníticos em níveis crustais rasos, representa o melhor exemplo de metamorfismo de contato, como descrito em diversas partes da crosta continental (Turner 1980, Yardley 1989). No Setor Ocidental do Escudo Sul-rio-grandense, a intrusão do Complexo Granítico São Sepé (CGSS) desenvolveu uma auréola de contato em rochas metassedimentares e metavulcânicas do Complexo Bossoroca (Koppe et al. 1985) (Fig. 1). O resfriamento do magma granítico provavelmente ocorre em duas etapas. A primeira, por transmissão de calor para as rochas encaixantes (condução) e, a segunda, pela circulação dos fluidos magmáticos associados aos produtos finais de cristalização (infiltração). As evidências texturais e estruturais encontradas nas rochas estudadas indicam que a cristalização de minerais por metamorfismo de contato é anterior a formação do sistema hidrotermal. Na região oeste do Escudo Sulrio-grandense o posicionamento do CGSS ocorreu a $550 \mathrm{Ma}$ (Remus et al., 2000), e representa o magmatismo da etapa pósorogênica e pós-colisional do Ciclo Brasiliano denominada Evento
Dom Feliciano (Chemale Jr.. 2000).

O objetivo deste trabalho é apresentar o resultado do estudo do metamorfismo térmico associado à intrusão do Complexo Granítico São Sepé, e integrar informações disponíveis na literatura com novos dados geológicos obtidos.

GEOLOGIAREGIONALECONTEXTOGEOTECTÔNICO O Complexo Granítico São Sepé (Sartori 1978), também denominado Granito São Sepé por Porcher et al. (1991), situa-se no extremo norte da porção ocidental do Escudo Sul-Riograndense, a sudoeste da cidade de São Sepé (Fig. 2). A porção aflorante deste maciço granítico apresenta forma pouco alongada segundo a direção NESW, com dimensões de aproximadamente $22 \mathrm{~km}$ de comprimento e $15 \mathrm{~km}$ de largura. A intrusão granítica gerou, por metamorfismo de contato, uma auréola termal nas rochas metavulcano-sedimentares situadas a sul do referido maciço. A transmissão de calor ainda foi acompanhada de intensa circulação de fluidos tardi-magmáticos.

O Granito Jaguari e o CGSS pertencem à série alcalina, de natureza

1 - E-mail: icmattos@sfigc.org.br

2 - CPGq - Centro de Estudos em Petrologia e Geoquímica, Instituto de Geociências, UFRGS. e-mail: ruy.philipp@ufrgs.br 

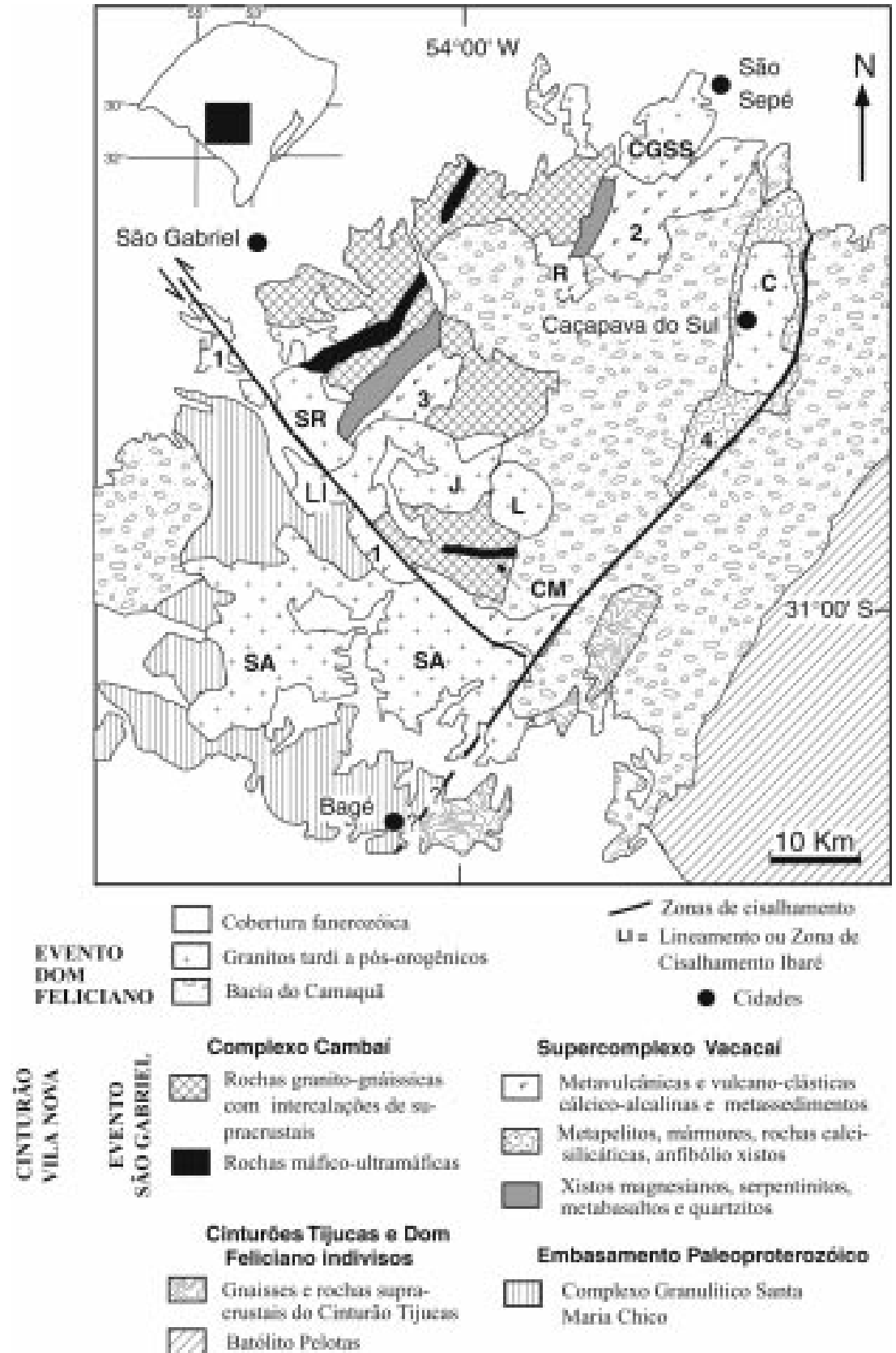

Figura 1 - Mapa geológico do Cinturão Vila Nova e do Terreno Taquarembó, com a localização do Complexo Granítico São Sepé (CGSS). 1 = Complexo Ibaré, 2 = Complexo Bossoroca, $3=$ Complexos Palma, $4=$ Complexo Passo Feio, CM = Metaultramafitos Cerro Mantiqueira. Corpos Graníticos: $C=$ Caçapava do Sul, $J=$ Jaguari, $L=$ Lavras, $R=$ Ramada, SA = Santo Afonso, SR=Santa Rita, SS = São Sepé (fonte: modificado de Chemale Jr. 2000).

metaluminosa, e aparentemente representam a última manifestação magmática Brasiliana na região, segundo Gastal et al. (1995). Hartmann \& Nardi (1983) sugerem que a afinidade química alcalina do CGSS é indicativa de posicionamento em ambiente cratônico ou em espessa margem continental.

O CGSS apresenta relações de contato intrusivas com os Complexos Bossoroca e Passo Feio, e com as rochas sedimentares e vulcânicas do Grupo Maricá. Ainda mantém relações com o Complexo Estratiforme Básico-Ultrabásico Pedras Pretas, que ocorre como um megaxenólito no interior do maciço. A intrusão do granito ocorreu em níveis crustais rasos desenvolvendo, sobre as rochas das coberturas metavulcano-sedimentares Neoproterozóicas e vulcano-sedimentares Eo-Paleozóicas, uma auréola de metamorfismo de contato com cerca de 2 a $4 \mathrm{~km}$ de extensão.

A exposição das rochas graníticas decorreu da erosão da Formação Rio Bonito que ainda cobre parte da sua porção periférica, principalmente a NW, N e NE. As principais transformações metamórficas estão registradas nas rochas do Complexo Bossoroca, situadas na porção sul e oeste do CGSS. Ao 


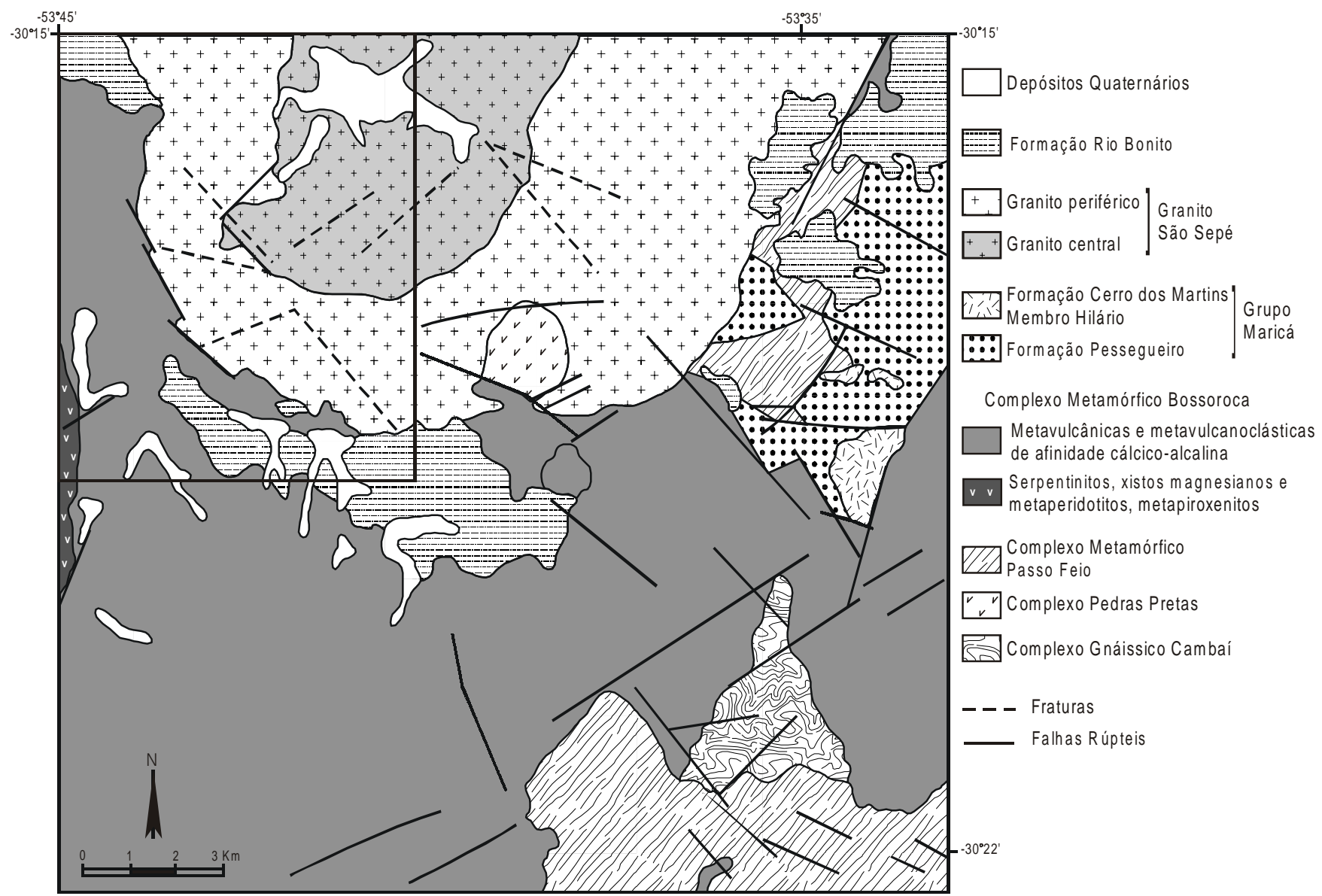

Figura 2 - Mapa geológico da porção noroeste da folha Passo do Salsinho (1:50.000), com indicação do mapa de semi-detalhe representado na figura 3, modificado de Porcher et al. (1991).

longo da borda E-SE do corpo granítico, ocorrem efeitos termais sobre as rochas sedimentares da Formação Pessegueiros e sobre as pequenas intrusões e lavas andesítico-basálticas do Membro Hilário, pertencente à Formação Cerro dos Martins, Grupo Maricá (Santos et al. 1989).

Nas rochas do Complexo Bossoroca, a transformação metamórfica se manifesta pelo desenvolvimento de cornubianitos sobre protólitos de composição pelítica e quartzo-feldspática e rochas metavulcânicas básicas. Nas rochas do Complexo Passo Feio houve crescimento de biotita e muscovita com textura decussada. Na Formação Pessegueiro as principais transformações consistem de litificação acentuada, obliteração das feições primárias e desenvolvimento de epidoto e actinolita na matriz de arenitos e siltitos tufáceos. Nas rochas vulcânicas do Membro Hilário, houve crescimento aleatório de actinolita, mica branca, epidoto e clorita sobre os minerais ígneos.

ROCHAS ENCAIXANTES As rochas encaixantes da região estudada pertencem ao Complexo Bossoroca (Koppe et al. 1985), sendo incluídas no Supercomplexo Vacacaí (Chemale Jr. 2000). O Complexo Bossoroca está representado pelas Seqüências Arroio Lajeadinho e Campestre. A primeira é composta por uma associação de xistos magnesianos e serpentinitos, subordinadamente metaperidotitos e metapiroxenitos. A segunda consiste de uma ampla associação de rochas metavulcânicas básicas e intermediárias, com metatufos e rochas metassedimen-tares químicas (chert) e de espesso pacote de metarenitos, metasiltitos e metargilitos vulcanogênicos. Na porção oeste, o CGSS é limitado da Seqüência Campestre através de uma importante zona de fraturamento de direção $\mathrm{N} 35-45^{\circ} \mathrm{W}$. Subordinadamente ocorrem fraturas de direção $\mathrm{N} 20-40^{\circ} \mathrm{E}$.

$\mathrm{Na}$ área de estudo, as unidades metamorfizadas caracterizam-se por rochas metavulcânicas de composição intermediária a básica, intercaladas por zonas de cisalhamento dúcteis a dúctil-rúpteis com metapelitos e metassedimentos quartzo-feldspáticos (Koppe et al. 1985, Zarpelon 1986, Porcher et al. 1991). Esta associação litológica compõe um pacote de filitos e xistos micáceos com orientação preferencial para nordeste e mergulhos elevados para sudeste. As rochas do Complexo Bossoroca foram submetidas inicialmente a um metamorfismo regional orogênico de baixo grau, com condições da fácies xisto verde inferior, como discutido por Hartmann \& Nardi (1983), Zarpelon (1986), Wildner (1990) e Hartmann et al. (2000). As rochas metamórficas do Complexo Bossoroca apresentam uma gradação das estruturas de orientação mineral relacionadas ao metamorfismo orogênico, até estruturas maciças resultantes do metamorfismo de contato.

CONDIÇÕES DE POSICIONAMENTO DO CGSS Sartori 
(1978) sugere que após o vulcanismo andesito-basáltico do Membro Hilário, pertencente à Formação Cerro dos Martins, seguiu-se um extenso magmatismo granítico. $\mathrm{O}$ posicionamento dos corpos plutônicos neste evento ocorreu em níveis crustais rasos, de epizona, gerando condições para o alojamento do magma ácido a altas temperaturas e com significativo teor de voláteis. A presença abundante de cavidades miarolíticas na porção de borda do CGSS, associadas com a diminuição do tamanho de grão, são indicativas do posicionamento em alto nível crustal. A presença de quartzo com forma globular a facetada, é sugestiva da elevada temperatura do magma e da sua afinidade alcalina. Ainda é importante observar que na área ocupada pela auréola de contato, as rochas encaixantes são cortadas por corpos pegmatíticos discretos e filões de quartzo leitoso contendo ouro e sulfetos (pirita e calcopirita), sugerindo a preservação parcial da porção de cúpula do granito.

A ocorrência de cornubianitos junto ao contato com o CGSS, indica o seu caráter intrusivo nos metamorfitos de baixo grau. A presença de estrutura maciça nas rochas graníticas indica colocação sob condições extensionais, que, associadas á presença de megaxenólitos de rochas básicas e ultrabásicas de natureza estratiforme (Complexo Pedras Pretas) apontam um mecanismo de posicionamento passivo do tipo stoping.

METAMORFISMO DE CONTATO A intrusão do CGSS gerou, nas rochas metamórficas de baixo grau da sequiência Campestre do Complexo Bossoroca, uma auréola de contato definida por uma faixa de cornubianitos com largura de dezenas a centenas de metros, atingindo extensão máxima de aproximadamente $5 \mathrm{~km}$ (Fig. 3).

Os cornubianitos de natureza pelítica são cinza-escuro a cinzaesverdeado, geralmente com elevada coesão, aspecto maciço e textura granoblástica média a grossa. Na faixa de contato com a intrusão, os cornubianitos estão intensamente recortados por veios de quartzo de direções variadas, veios de actinolita e, subordinadamente, veios submilimétricos de epidoto. Nos metapelitos, um bandamento composicional plano-paralelo é interpretado como estrutura sedimentar reliquiar.

Ao microscópio, as amostras evidenciam diferenças texturais e mineralógicas que refletem variações na composição original e no grau de metamorfismo alcançado nos vários pontos da auréola. A partir da coleta e da realização de análises petrográficas em 45 amostras, foi definida a zonação metamórfica nas rochas cornubianíticas (Fig. 3). Assim, em função das rochas encaixantes estarem constituídas por uma intercalação de rochas metapelíticas e metavulcânicas, observa-se uma associação metamórfica distinta para cada seqüência.

As paragêneses dos cornubianitos metapelíticos possuem uma zonação térmica, com uma auréola externa na zona da biotita, intermediária na zona da granada e, próximo ao granito, na zona da estaurolita (Mattos 1997). Nas duas últimas ocorrem, também, amplo desenvolvimento de porfiroblastos de andaluzita. As paragêneses encontradas correspondem a condições de metamorfismo da fácies albita-epidoto cornubianito e hornblenda cornubianito. Na porção mais interna do contato, as rochas metabásicas a metandesíticas possuem assembléia mineral com hornblenda actinolítica + plagioclásio sódico + quartzo \pm biotita \pm epidoto, o que também também situar o grau de metamorfismo na fácies hornblenda cornubianito.

Petrografia dos Cornubianitos Pelíticos O efeito térmico do corpo granítico nas encaixantes gerou cornubianitos pelíticos cinzaescuro a claro, de coesão muito elevada, estrutura maciça e texturas

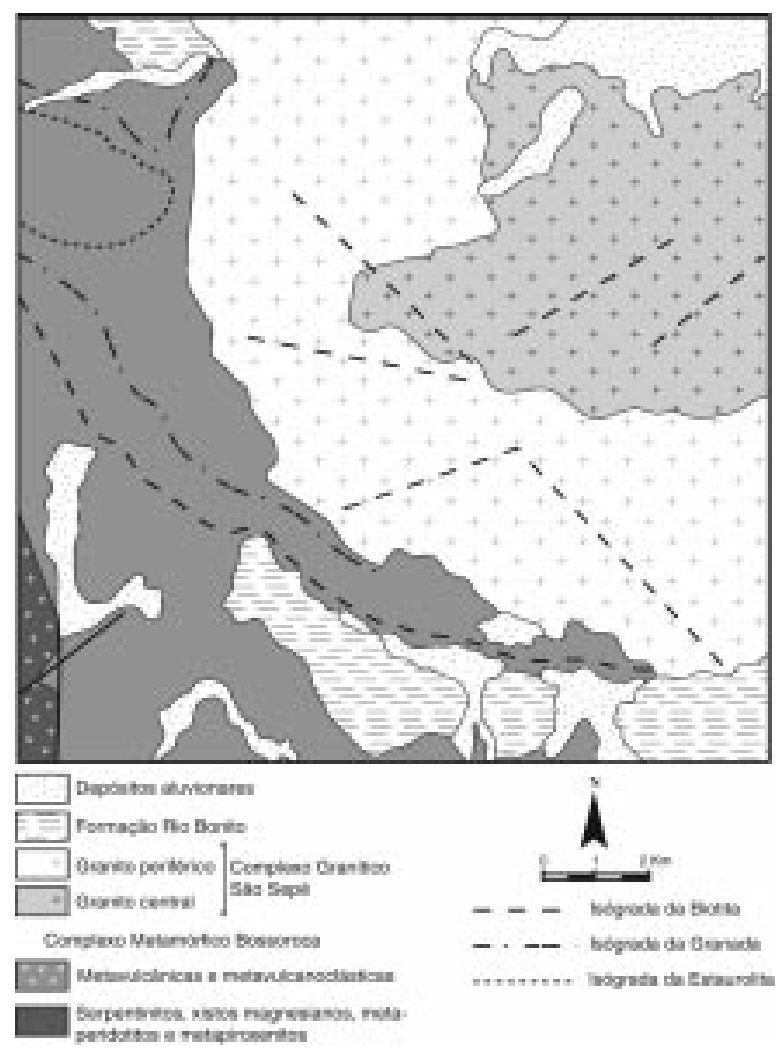

Figura 3 - Mapa geológico do Complexo Granítico São Sepé com a indicação das isógradas de metamorfismo termal, detalhe da figura 2.

porfiroblásticas típicas do metamorfismo de contato. Nos metapelitos, a alternância de níveis com textura granoblástica ricos em quartzo e níveis lepidoblásticos com biotita e muscovita, evidencia um bandamento composicional sedimentar, bem como a cristalização de minerais sobre paragêneses metamórficodeformacionais anteriores (Fig. 4a). A presença de estruturas sedimentares reliquiares e a transição, em campo, dos cornubianitos maciços para filitos e xistos pelíticos, metarenitos, metasiltitos e metargilitos vulcanogênicos, indicam que as rochas afetadas termalmente pela intrusão do CGSS pertencem ao Complexo Bossoroca.

A principal caraterística dos cornubianitos metapelíticos é o desenvolvimento de uma estrutura maculosa e nodulosa definida pela presença de porfiroblastos de andaluzita e, subordinadamente, de granada (Fig. 4b). Os porfiroblastos estão imersos em uma matriz granoblástica poligonal, equigranular a inequigranular média a grossa. A matriz apresenta composição rica em quartzo, sendo constituída também por agregados micáceos de muscovita e biotita, produtos de um crescimento mimético (Fig. 4c). A andaluzita ocorre como poiquiloblastos de dimensões entre 4 a $25 \mathrm{~mm}$, xenoblásticos a subordinadamente hipidioblásticos, com inclusões de granada, biotita e quartzo. A estaurolita ocorre como cristais diminutos, com formas xenoblásticas a hipidioblásticas, sendo de ocorrência restrita, principalmente próximo ao Passo da Juliana (Fig. 4d).

O quartzo é abundante e ocorre na matriz com forma poligonal e tamanho entre 0,1 a $0,3 \mathrm{~mm}$. É o principal mineral a constituir a textura granoblástica. Representa 18 a $40 \%$ do volume modal da rocha. Pode ocorrer ainda preenchendo veios com espessuras 

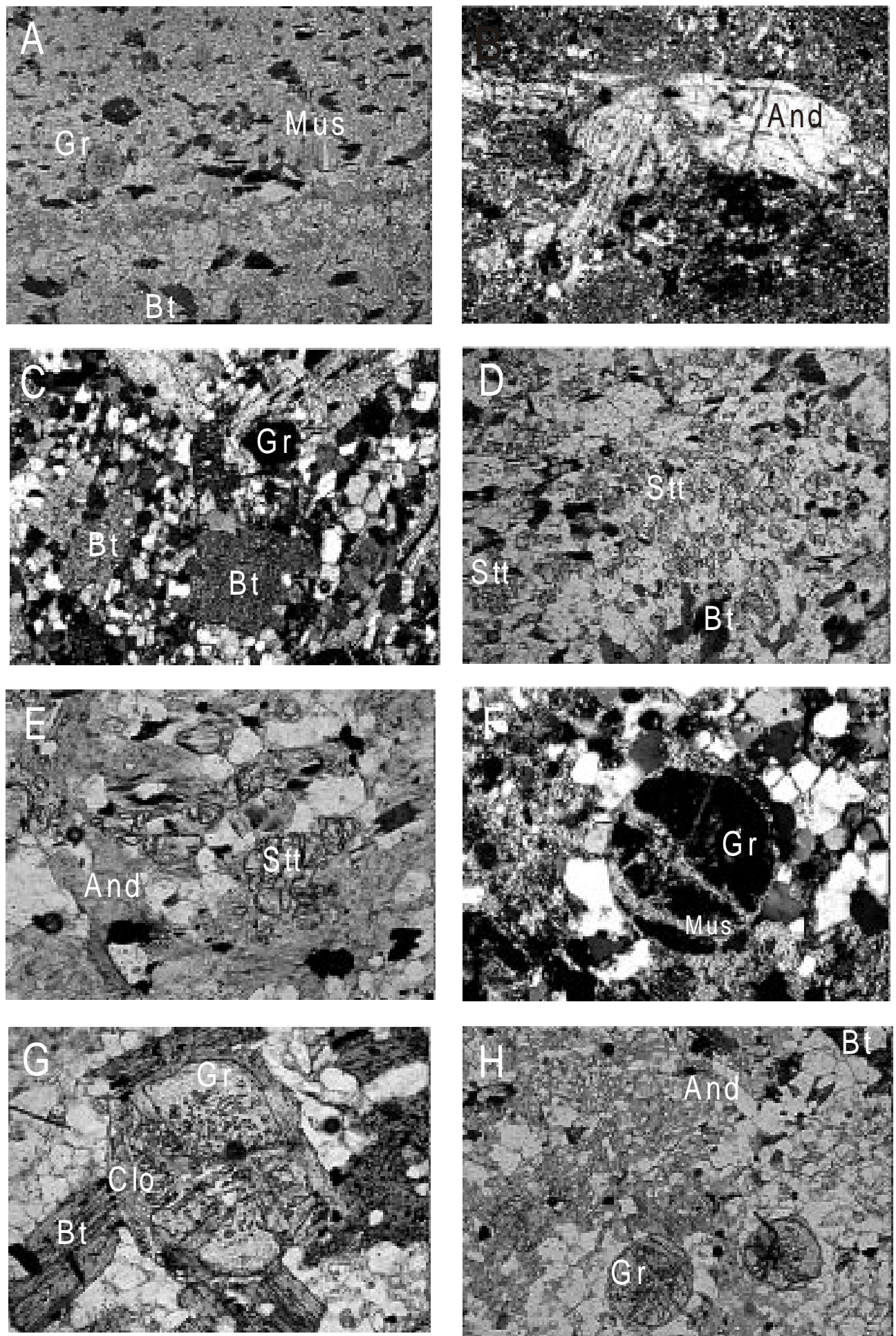

Figura 4 - Fotomicrografias das paragêneses do metamorfismo de contato em cornubianitos pelíticos da transformação hidrotermal das mesmas pelos fluídos tardi-magmáticos. A) Amostra da zona da Biotita, apresentando textura lepidoblástica do metamorfismo regional, com crescimento desorientado de muscovita e biotita, luz natural, aumento 25 X. B) Porfiroblastos de andaluzita, luz polarizada, aumento 25 X. C) Amostra da zona da Granada, com porfiroblastos de biotita e granada, em matriz com textura granoblástica poligonal, luz polarizada, aumento 50 X. D) Amostra da zona da Estaurolita com diminutos cristais subidioblásticos de estaurolita, luz natural, aumento 25 X. E) Paragênese de temperatura mais elevada com porfiroblastos de andaluzita e estaurolita, luz natural, aumento 25 X. F) Porfiroblasto de granada com crescimento tardio de muscovita e clorita, luz polarizada, aumento 100 $X . G)$ Porfiroblasto de granada com crescimento tardio de clorita em fraturas, luzpolarizada, aumento $100 X$. H) Pseudomorfos de porfiroblastos de andaluzita transformados em mica branca, e granada com crescimento de clorita em fraturas, luz polarizada, aumento $50 \mathrm{X}$. 
inferiores a $20 \mathrm{~mm}$ e direções variadas. A biotita é comum, aparecendo como cristais subidioblásticos de 0,2 a 3,0 mm, podendo ocorrer na matriz e como porfiroblastos de contatos irregulares. As características petrográficas da biotita permitem definir duas gerações: 1) biotita precoce, formada durante o metamorfismo regional orogênico, 2) biotita tardia, gerada no metamorfismo de contato (Figuras $4 \mathrm{a}, \mathrm{c}, \mathrm{g}$ ). A biotita gerada no metamorfismo orogênico ocorre como agregados orientados formando a textura lepidoblástica. A biotita gerada pelo metamorfismo de contato ocorre como porfiroblastos esqueléticos com tamanhos entre 0,5 e $3 \mathrm{~mm}$. Freqüentemente, mostram inclusões de quartzo, albita e minerais opacos. Os limites dos porfiroblastos são interlobados, estando comumente alterados para mica branca. Destaca-se em lâmina pela sua textura maculosa, observada nas rochas ao longo do Passo do Engenho. A granada é do tipo almandina, ocorrendo como cristais subidioblásticos a idioblásticos, com contatos regulares e formas globulares (Figs. 4a,c,f). Apresentam tamanhos variáveis entre 0,1 a $1 \mathrm{~mm}$ e mostram-se dispersas aleatoriamente na matriz. Inclusões poiquiloblásticas de quartzo e feldspato são comuns. Próximo aos veios de quartzo, as granadas mostram efeitos retrometamórficos, sendo envoltas por lamelas de mica branca e clorita. Apresenta uma variação de 1 a $8 \%$ na composição modal dos cornubianitos metapelíticos. O plagioclásio presente na matriz é do tipo albita, com forma equidimensional subidioblástica, contornos regulares, raramente apresentando geminações simples. Em alguns locais, possuem inclusões de minerais opacos e pequenos cristais de mica. $\mathrm{O}$ tamanho varia de 0,1 a $0,5 \mathrm{~mm}$ e representa, como constituinte mineral da rocha, de 5 a $15 \%$. A andaluzita ocorre próximo ao contato do CGSS com os metassedimentos do Complexo Bossoroca, ao longo da região do Passo da Juliana. Constituem cristais poiquiloblásticos, apresentando inúmeras inclusões de biotita, quartzo e albita, mais raramente, de granada. Os contatos são bastantes irregulares. Os cristais são anédricos e bem desenvolvidos, atingindo até $30 \mathrm{~mm}$ de comprimento. A presença de um evento retrometamórfico está marcada por uma intensa desestabilização da andaluzita e formação de mica branca sobre os porfiroblastos (Figs. 4e,h). A estaurolita é relativamente rara, com cristais xenomórficos apresentando forma esquelética. Os cristais são pequenos, inferiores a $0,1 \mathrm{~mm}$, apresentando por vezes, inclusões de quartzo (Figs. 4c,e).

Um evento tardio está caracterizado pela desestabilização e intensa hidratação da paragênese do metamorfismo de contato. Este processo está registrado, principalmente, pelo crescimento de mica branca fina sobre andaluzita, clorita sobre granada e mica branca e epidoto sobre plagioclásio. A clorita tem formas xenoblásticas, contatos irregulares e ocorre de maneira dispersa pela matriz ou ainda como pequenos agregados (Fig. 4g). Mais freqüentemente resulta da alteração hidrotermal (cloritização) da biotita, principalmente próxima a vênulos de quartzo. O tamanho pode variar de 0,1 a $0,5 \mathrm{~mm}$. Constitui 0,5 a $2 \%$ das amostras analisadas. A mica branca é bastante comum na matriz destas rochas, ocorrendo como finíssimas lamelas subidioblásticas, alguns cristais apresentam disposição ligeiramente orientada, provenientes da substituição de porfiroblastos de biotita e de andaluzita. Os contatos são irregulares e o tamanho está em torno de $0,1 \mathrm{~mm}$. Compõem de 5 a $10 \%$ da rocha. O epidoto é relativamente raro. São cristais pequenos ( 0,1 a $0,2 \mathrm{~mm})$ com forma xenoblástica. Os limites são irregulares, normalmente estão em contato com a clorita ou incluso na biotita. O epidoto ocorre também preenchendo microfraturas, dispostos como finas lamelas bem cristalizadas. Constitui até $3 \%$ das amostras analisadas. Os minerais opacos encontrados nos cornubianitos de composição metapelítica são a magnetita, ilmenita, pirita, rutilo e pirrotita. A pirita ocorre com forma cúbica subédrica, esparsa na matriz e com bordos oxidados. A ilmenita está associada a clorita como pequenos cristais e como minerais opacos ripiformes identificados como rutilo. Uma análise petrográfica detalhada revelou a presença de pirrotita associada à pirita. Como acessórios comuns ocorre ainda a apatita, e subordinadamente, a turmalina idioblástica na forma de cristais muito pequenos.

Petrografia dos Cornubianitos Básicos a Intermediários As rochas encaixantes de composição básica a intermediária estão caracterizadas na região da auréola de metamorfismo de contato por protólitos como meta-arenitos e metasiltitos vulcanogênicos, e rochas metavulcânicas (metabasaltos e metandesitos). Esta sequiência metamórfica mostra registros do metamorfismo regional orogênico de grau baixo, em condições equivalentes às da fácies Xistos Verdes inferior a médio. Os cornubianitos básicos apresentam uma estrutura maciça com textura granoblástica inequigranular poligonal a interlobada média $(0,2$ a 0,4 mm). Quando muito ricos em anfibólio podem apresentar textura decussada. Apresentam cor cinza esverdeado médio a preto, com vênulos e veios de quartzo, milimétricos e desorientados. A textura dominante é porfiroblástica, definida pelo crescimento de grandes cristais de anfibólio. A presença de textura granoblástica é comum, ocorrendo na matriz uma paragênese que inclui clorita + actinolita + albita \pm epidoto \pm biotita \pm quartzo. São comuns veios de quartzo, de epidoto e de actinolita milimétricos a centimétricos. Cortam a rocha sem orientação preferencial. Veios de actinolita contendo anfibólio com tamanhos de até $4 \mathrm{~cm}$ são comuns. Os veios contendo actinolita e epidoto são mais tardios e cortam os veios de quartzo.

O plagioclásio ocorre numa proporção modal de 10 a $40 \%$, como cristais metamórficos de albita, de formas equidimensionais subidioblásticas, com contatos irregulares e tamanhos em torno de 0,3 a 0,6 mm. Mostram-se alterados para mica branca e epidoto. Em algumas seções delgadas de metabasaltos e metandesitos foram identificados antigos fenocristais de plagioclásio com forma prismática euédricos a subédricos e tamanhos de 1,5 a $2,5 \mathrm{~mm}$, macla polissintética e zonação normal. O anfibólio é de dois tipos: actinolita e hornblenda, ocorrendo em proporções modais variáveis de 15 até $50 \%$. A actinolita ocorre na matriz, caracterizando-se por cristais de tamanho médio em torno de 0,2 a $0,6 \mathrm{~mm}$, com pleocroísmo variando de castanho-esverdeado ao azul esverdeado. Possuem hábitos aciculares, formando agregados fibro-radiados ou dispersos na matriz, em tamanhos e direções variadas. Podem estar intercrescidos com opacos xenoblásticos. Os porfiroblastos de hornblenda possuem dimensões entre 0,3 a 2,0 mm, ocorrem com formas xenoblásticas a subidioblásticas, constituindo a textura poiquiloblástica. São comuns na maioria dos cristais, inclusões de minerais opacos e, mais raras, de epidoto. A actinolita aparece também como veios preenchendo fraturas nos cornubianitos metabásicos, gerando agregados de cristais bem desenvolvidos $(0,5$ a $1,5 \mathrm{~cm})$, alternando com cristais submilimétricos em arranjo granoblástico. Os cristais de quartzo ocorrem de forma subordinada e mostram forma poligonal com limites retos. Ocupam uma posição intersticial com tamanhos entre 0,1 a $0,4 \mathrm{~mm}$. Formas subidioblásticas são mais comuns que os cristais xenoblásticos. Constituem aproximadamente 1 a $3 \%$ do volume modal. Menos freqüente, aparece em veios e em agregados de tamanhos maiores, associados a actinolita. A biotita é relativamente rara, mostrando cor avermelhada com bordos 
interlobados e aspecto esquelético, variando de subidioblástica a xenoblástica, com tamanho entre 0,2 a $2 \mathrm{~mm}$. Quando associada à actinolita, apresenta-se geralmente cloritizada e freqüentemente com inclusões de opacos. A quantidade de biotita varia de 0,5 a $3 \%$ das amostras analisadas.

A clorita é produto de alteração da biotita e da actinolita, substituindo-as pseudomorficamente. Pode ocorrer em veios ou dispersa na matriz, associada a actinolita e ao quartzo. Esta cloritização está associada à fase de alteração hidrotermal. A mica branca resulta de alteração do plagioclásio, como massas lamelares ou finas lamelas disseminadas de aproximadamente $0,1 \mathrm{~mm}$. Os minerais opacos ocorrem como cristais xenoblásticos, mais raramente idioblásticos e constituem cerca de 1 a $5 \%$ do volume modal da rocha. São comuns no contato entre os veios e a rocha, limitando os veios de actinolita com quartzo. Nestes casos, apresentam bordos corroídos. Os minerais opacos das rochas metabásicas são magnetita, ilmenita e pirita. A magnetita é subédrica e de dimensões pequenas na matriz, mas anédrica e maior junto a actinolita dos veios. É, em geral, irregular com muitas inclusões e algumas apresentam exsolução de hematita. A ilmenita também está associada a actinolita, mas em proporções menores, não apresenta forma definida e ocorre como massa irregular. A pirita está geralmente inclusa na ilmenita, é euédrica e também ocorre com bordos corroídos. Ocorre em menor proporção e tamanho que a ilmenita. Leucoxênio (anatásio) ocorre como película amarela de alteração da ilmenita.

\section{CONDIÇÕESMETAMÓRFICASDOSCORNUBIANITOSES-}

TUDADOS A análise petrográfica dos cornubianitos metapelíticos permitiu determinar as isógradas e a zonação do metamorfismo de contato, com intervalos específicos de temperatura nas rochas encaixantes, ao longo do contato com o CGSS (Fig. 3). No halo mais externo ao contato, a reduzida influência térmica do granito manifesta-se pela preservação da estrutura xistosa, com desenvolvimento subordinado de paragêneses de temperatura baixa (zona da biotita). A porção mais extensa corresponde à zona da granada, associada a um largo intervalo de temperatura onde a andaluzita é o principal porfiroblasto. No contato oeste, a zona da estaurolita ocorre de forma mais restrita e, em planta, de forma elíptica alongada segundo NW. Esta zona está relacionada a temperaturas mais elevadas, acima de $520^{\circ} \mathrm{C}$. A disposição espacial da isógrada da estaurolita permite supor, que em subsuperfície, a forma do granito neste local é aproximadamente suborizontal. Os geotermômetros a seguir descritos corroboram estas observações pelas temperaturas estimadas para a zona da estaurolita.

As zonas de metamorfismo de contato e as paragêneses dos cornubianitos metapelíticos compreendem:

Zona da Biotita: Qzo+Musc+Bt+-Ab+Op;

Zona da Granada: Qzo+Musc+Bt+Gran+And+Ab+Op;

Zona da Estaurolita: Qzo+Gran+And+Stt+Bt+Olig+Op;

Uma última transformação com ocorrência irregular e caráter tardio está definida pelas paragêneses hidrotermais como: Qzo+Mica Branca+Clo+-Ep+-Act+Carbonato+Sulfetos+Ouro.

CARACTERIZAÇÃO QUÍMICA DOS MINERAIS DO METAMORFISMO DE CONTATO Oestudo da química mineral foi realizado nos cornubianitos pelíticos, em minerais formados pelo metamorfismo de contato (biotita, granada, andaluzita e estaurolita) e também nos minerais que pertencem à fase de alteração hidrotermal (clorita, mica branca, epidoto e minerais opacos).
Tabela 1 - Análises representativas dos minerais dos cornubianitos metapelíticos. Resultados em \% em peso dos óxidos e na fórmula estrutural. Base de 20 oxigênios para cristais de andalusita, 48 para a estaurolita, 11 para a biotita e 12 para a granada.

\begin{tabular}{|c|c|c|c|c|c|c|}
\hline \multirow{2}{*}{$\mathrm{SiO}_{2}$} & \multicolumn{2}{|c|}{ ANDALUSIT A } & \multicolumn{2}{|c|}{ ESTAUROLITA } & \multicolumn{2}{|c|}{ BIOTIT A } \\
\hline & 37,40 & 37,59 & 28,07 & 26,72 & 35,05 & 35,40 \\
\hline $\mathrm{Al}_{2} \mathrm{O}_{3}$ & 62,25 & 61,98 & 53,01 & 53,17 & 18,99 & 19,21 \\
\hline $\mathrm{FeO}$ & 1,10 & 1,21 & 12,95 & 12,93 & 21,07 & 19,34 \\
\hline $\mathrm{Fe}_{2} \mathrm{O}_{3}$ & 0,00 & 0,00 & 0,00 & 0,00 & 0,00 & 0,00 \\
\hline $\mathrm{MgO}$ & 0,02 & 0,03 & 1,12 & 1,10 & 8,95 & 9,40 \\
\hline $\mathrm{TiO}_{2}$ & 0,01 & 0,04 & 0,70 & 0,54 & 1,36 & 1,86 \\
\hline $\mathrm{MnO}$ & 0,00 & 0,00 & 0,37 & 0,43 & 0,30 & 0,12 \\
\hline $\mathrm{CaO}$ & 0,03 & 0,02 & 0,03 & 0,00 & 0,01 & 0,03 \\
\hline $\mathrm{Na}_{2} \mathrm{O}$ & 0,05 & 0,03 & 0,00 & 0,00 & 0,11 & 0,12 \\
\hline $\mathrm{K}_{2} \mathrm{O}$ & 0,00 & 0,00 & 0,02 & 0,03 & 9,04 & 9,29 \\
\hline Total & 100,87 & 100,90 & 96,27 & 94,92 & 95,01 & 94,39 \\
\hline $\mathrm{Si}$ & 4,02 & 4,04 & 8,23 & 7,96 & 2,70 & 2,69 \\
\hline $\mathrm{Al}$ & 7,89 & 7,89 & 18,31 & 18,67 & 1,72 & 1,74 \\
\hline $\mathrm{Fe}^{2+}$ & 0,10 & 0,10 & 3,17 & 3,22 & 1,36 & 1,24 \\
\hline $\mathrm{Fe}^{3+}$ & 0,00 & 0,00 & 0,00 & 0,00 & 0,00 & 0,00 \\
\hline $\mathrm{Mg}$ & 0,00 & 0,00 & 0,49 & 0,49 & 1,03 & 1,08 \\
\hline $\mathrm{Ti}$ & 0,00 & 0,00 & 0,15 & 0,12 & 0,08 & 0,11 \\
\hline $\mathrm{Mn}$ & 0,00 & 0,00 & 0,09 & 0,11 & 0,02 & 0,01 \\
\hline $\mathrm{Ca}$ & 0,00 & 0,00 & 0,01 & 0,00 & 0,00 & 0,00 \\
\hline $\mathrm{Na}$ & 0,01 & 0,10 & 0,00 & 0,00 & 0,02 & 0,02 \\
\hline $\mathrm{K}$ & 0,00 & 0,00 & 0,01 & 0,01 & 0,89 & 0,91 \\
\hline $\begin{array}{c}\mathrm{Fe}^{2}+\mathrm{Mg} \\
\mathrm{Fe}^{2} / \mathrm{Fe}^{2}+\mathrm{M}\end{array}$ & --- & --- & --- & --- & 2,38 & 2,32 \\
\hline $\mathrm{g}$ & --- & --- & --- & --- & 0,57 & 0,54 \\
\hline $\mathrm{Al}^{\mathrm{IV}}$ & --- & --- & --- & --- & 1,30 & 1,31 \\
\hline $\mathrm{Al}^{\mathrm{IV}}$ & --- & --- & --- & --- & 0,42 & 0,43 \\
\hline
\end{tabular}

As análises foram realizadas no Laboratório de Microssonda Eletrônica do Centro de Estudos em Petrologia e Geoquímica (CPGq), do Instituto de Geociências da UFRGS. O equipamento utilizado foi uma Microssonda CAMECA modelo SX 50. Os dados químico-mineralógicos dos principais minerais gerados no metamorfismo de contato constam da Tabela 1.

Biotita A biotita do metamorfismo de contato apresenta concentrações de $\mathrm{Fe}^{2+}$ e $\mathrm{Ti}^{4+}$ inferiores, e concentrações de $\mathrm{Al}^{\text {total }}{\mathrm{e} \mathrm{Mg}^{2+}}^{2+}$ mais altos, quando comparadas à biotita do granito. Tanto o teor de $\mathrm{Fe}^{2+}$ baixo quanto o $\mathrm{Al}^{3+}$ elevado podem estar relacionados com a composição pelítica da rocha. $\mathrm{O} \mathrm{Ti}^{4+}$ na biotita do cornubianito tem valores inferiores a metade dos observados na biotita do granito periférico $(0,10)$, o que sugere origem metamórfica de baixa temperatura (inferior à magmática, $\mathrm{Ti}^{4+}=0,22$ ). Os valores de $\mathrm{Mg}^{2+}$ são elevados, assim como o $\mathrm{Al}^{\mathrm{VI}}$, e pode representar um relativo grau de substituição nas camadas octaédricas. O diagrama $\mathrm{Al}{ }^{\mathrm{VI}} \times \mathrm{Mg} / \mathrm{Mg}+\mathrm{Fe}$ mostra que ambos tipos petrográficos de biotita tendem à composição da anita (Fig. 5).

Andaluzita A andaluzita mostra teores médios de $37 \%$ de $\mathrm{SiO}_{2} \mathrm{e}$ $62 \%$ de $\mathrm{Al}_{2} \mathrm{O}_{3}$, caracterizando os cornubianitos com protólito de composição pelítica. A ocorrência de Andaluzita permite definir um intervalo de pressão e temperatura para a cristalização destas rochas. A associação Andaluzita+Estaurolita+Quartzo apresenta um equilíbrio estável em pressões entre 2,2 e $5 \mathrm{~Kb}$ e temperaturas de cerca de 520 e $600^{\circ} \mathrm{C}$ (Yardley 1989, Bucher \& Frey 1994) (Fig. 6). Como os geotermômetros, utilizados nas rochas em estudo, 
revelam temperaturas entre $580^{\circ}$ e $690^{\circ}$, a presença de Andaluzita pode indicar que as pressões, nos xistos durante o metamorfismo de contato, não foram inferiores $2,5 \mathrm{~Kb}$.

Granada A granada tem composição homogênea, sem

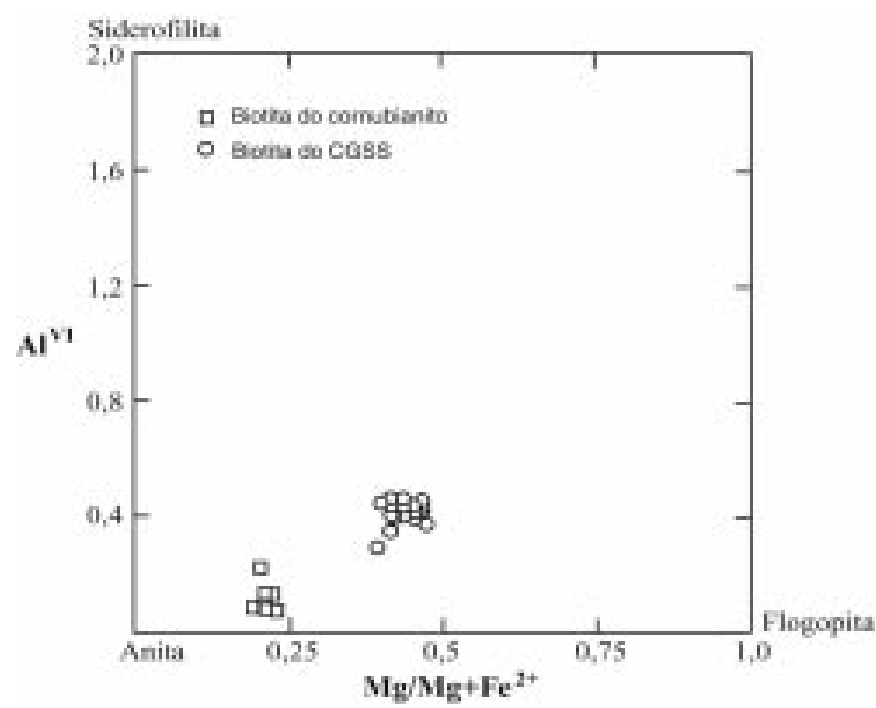

Figura 5 - Diagrama $\mathrm{Al}^{V I}$ versus $\mathrm{Mg} / \mathrm{Mg}+\mathrm{Fe}^{2+}$ para as biotitas metamórficas geradas em cornubianitos metapelíticos e magmáticas do Complexo Granítico São Sepé.

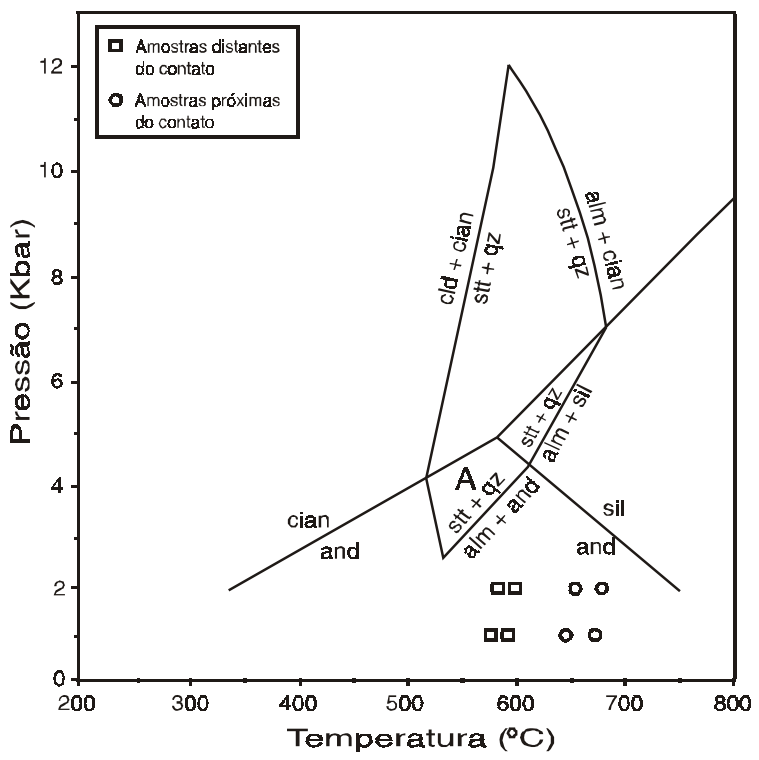

Figura 6 - Diagrama petrogenético de equilíbrio de fases de metapelitos com destaque do campo de ocorrência da estaurolita (Yardley 1989, Butcher \& Frey 1994), dos polimorfos de $\mathrm{Al}_{2} \mathrm{SiO}_{5}$ (Cianita/Andaluzita/Silimanita) e com as temperaturas obtidas nos geotermômetros testados em pressões de 1 e 2 kbarias. $A=$ Campo da assembléia mineral de temperatura mais elevada encontrada nos cornubianitos metapelíticos do Complexo Granítico São Sepé. zoneamento químico interno, confirmando sua origem no metamorfismo de contato (cristalização rápida sem variação composicional do núcleo para as bordas). Foram analisados 5 cristais ao longo de perfis do centro para os bordos, com cinco determinações cada. As variações observadas nas concentrações de $\mathrm{Mn}^{2+}$ ocorrem somente entre diferentes amostras de granada (amostras 1 e 2, Fig. 7). Os resultados das análises em óxidos foram recalculados para a fórmula estrutural da granada utilizados em geotermômetros, adiante detalhados.

Estaurolita A estaurolita, como a andaluzita, também caracteriza a natureza aluminossilicática do protólito, devido a sua composi-

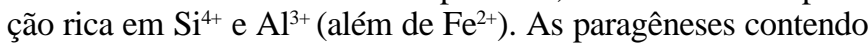
andaluzita, inicialmente Andaluzita + Granada, determinam o grau mais elevado de metamorfismo da fácies Albita-Epidoto Cornubianito. Porém, a ocorrência de estaurolita revela que o metamorfismo de contato alcançou a fácies Hornblenda Cornubianito (Yardley 1989, Bucher \& Frey 1994).

Geotermômetro Biotita-Granada As análises petrográficas confirmam estas fases na paragênese do metamorfismo de contato evidenciando também, o equilíbrio entre estes dois minerais. Desta maneira, as análises químicas de cristais de granada e de biotita foram utilizadas para o desenvolvimento de cálculos de geotermometria. Os cálculos dos geotermômetros de Ferry \& Spear (1977), Hodges \& Spear (1982) e Ganguly \& Saxena (1984) com suas respectivas calibragens mostram temperaturas que variam de $580^{\circ}$ a $710^{\circ}$ para amostras mais distantes e $585^{\circ}$ a $720^{\circ}$ para as mais próximas do contato, com pressões inferidas de 1 a $2 \mathrm{~kb}$. O geotermômetro Spear \& Kohn (1990), que reúne trabalhos de dez diferentes autores, incluindo os anteriormente citados, foi testado para o par biotita-granada em condições de pressões estimadas de 1 a 2 kbar. Estes valores estão próximos da pressão litostática em que se encontravam os metapelitos durante o posicionamento do granito. Com estes dados, obtiveram-se temperaturas de cristalização do par granada-biotita variáveis entre $590^{\circ} \mathrm{C}$ e $610^{\circ} \mathrm{C}$ em

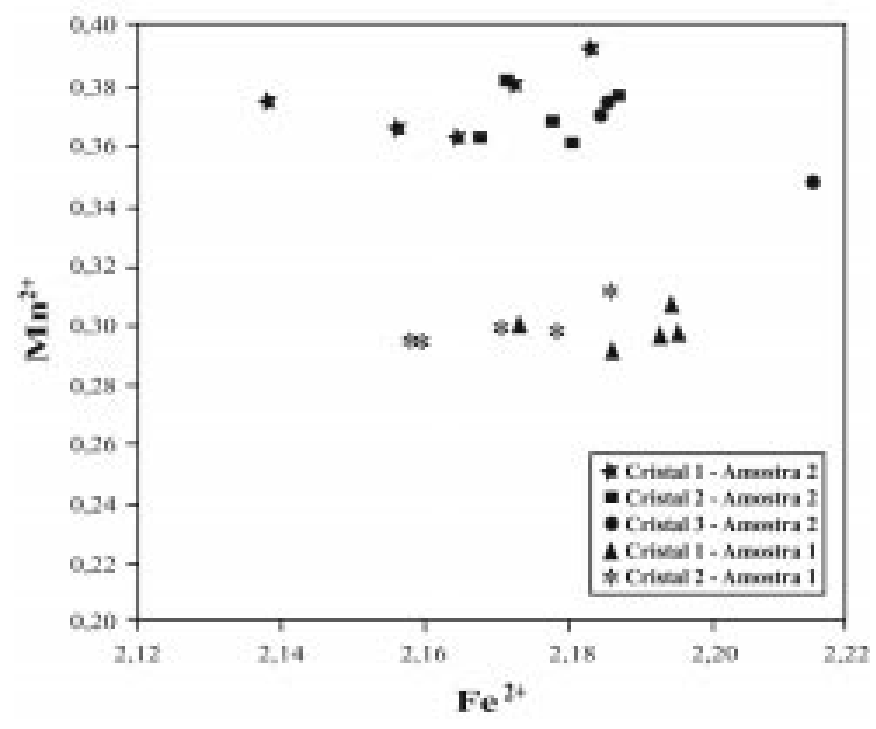

Figura 7-Diagrama Mn versus Fe mostrando a restrita variação composicional da granada dos cornubianitos metapelíticos por metamorfismo de contato do Complexo Granítico São Sepé. 
amostras em torno de $2,0 \mathrm{~km}$ do contato com o granito, e $596^{\circ} \mathrm{C}$ a $650{ }^{\circ} \mathrm{C}$ nas mais próximas, em torno de $1 \mathrm{~km}$. Estas temperaturas foram plotadas no diagrama $\mathrm{P} / \mathrm{T}$ com os campos dos minerais polimorfos de alumínio (Fig. 6).

As temperaturas obtidas por meio de geotermômetros do par biotita/granada e a disposição da isógrada da estaurolita podem indicar que o contato granito/cornubianito estende-se de forma suborizontal, visto que não ocorre um decréscimo de temperatura em relação ao aumento da distância do corpo granítico nas amostras de cornubianitos analisadas.

A pouca variação de temperatura obtida nos geotermômetros testados entre a região mais afastada e mais próxima do corpo granítico, aliado ao alto valor médio obtido para o equilíbrio da paragênese não é compatível com a posição de enquadramento da paragênese principal contendo Qzo+Gran+And+Stt+Bt na grade petrogenética dos metapelitos (Fig. 6). A presença de soluções hidrotermais e as conseqüentes transformações parciais dos minerais também podem ter contribuído para a variação dos valores obtidos com os geotermômetros testados.

O diagrama de fase mais representativo da paragênese da zona mais interna da auréola de contato está ilustrado na figura 6 . No diagrama, as análises situam-se no campo assinalado, em que a paragênese Gran+And+Stt delimitam condições termodinâmicas de temperaturas no intervalo entre 520 e $620^{\circ} \mathrm{C}$ e pressões entre 2,5 e 5 kbares. As temperaturas em torno de $570^{\circ}$ a $600^{\circ} \mathrm{C}$ são consideradas as mais prováveis para as rochas que estavam mais próximas ao contato com o magma granítico. Estas condições estabelecem, para esta região, temperaturas compatíveis com as da fácies Hornblenda Cornubianito, decrescendo para a fácies Ab-Ep Cornubianito a medida que nos afastamos do complexo granítico.

CONCLUSÕES O metamorfismo de contato gerado pela intrusão do Complexo Granítico São Sepé afetou as rochas metavulcanosedimentares do Complexo Bossoroca e os sedimentos do Grupo Maricá. Esta relação indica que a colocação do CGSS é um dos últimos eventos tectônicos da região e posterior a deposição das unidades basais da Bacia do Camaquã.

A zonação do metamorfismo de contato, caracterizada pelas isógradas da Biotita, Granada e Andaluzita-Estaurolita é indicativa da transição entre a fácies Albita-Epidoto Cornubianito e Hornblenda Cornubianito, registrando temperaturas máximas de $620-630^{\circ} \mathrm{C}$ e pressões entre 2,2 e 5 kbarias. A presença de uma fácies petrográfica de bordo com textura equigranular fina e cavidades miarolíticas também é indicativa da colocação do granito em níveis crustais rasos, de epizona.

O equilíbrio de fases do metamorfismo de contato em metapelitos baseado na interpretação da assembléia mineral e nas curvas de equilíbrio disponíveis em grades petrogenéticas mostra-se eficiente e confiável para rochas com paragêneses apropriadas. A quantificação da pressão absoluta no metamorfismo de contato é muito difícil e a aplicação de geotermobarômetros sem o controle de primeira ordem fornecida pela assembléia mineral pode não revelar informações suficientemente precisas.

O resfriamento do magma que gerou o CGSS pode ser compreendido como um processo contínuo desenvolvido em uma etapa inicial de transferência de calor para a encaixante, e uma posterior, de circulação de fluídos tardi-magmáticos. Esta relação se caracteriza pela formação inicial de texturas e paragêneses de metamorfismo de contato e sua posterior desestabillização hidrotermal.

Agradecimentos Ao apoio do Instituto de Geociências da UFRGS, ao CNPq pela concessão de bolsa de mestrado para o autor principal e, aos revisores da RBG pelas sugestões ao manuscrito.

\section{Referências}

Butcher K. \& Frey M. (Eds.) 1994. Petrogenesis of Metamorphic Rocks. Springer-Verlag, Berlin, 318p.

Chemale Jr. F. 2000. Evolução Geológica do Escudo Sul-rio-grandense. In: M. Holz, \& L. F. De Ros (eds.) Geologia do Rio Grande do Sul. CIGO-UFRGS, Porto Alegre, pp. 13-52.

Ferry J.M. \& Spear F.S. 1977. Experimental Calibration of Partitioning of $\mathrm{Fe}$ and $\mathrm{Mg}$ between biotite and garnet. Contrib. Mineral. Petrol., 66:113-117.

Ganguly J. \& Saxena S.K. 1984. Mixing properties of aluminosilicate garnets: contrains from natural and experimental data, and applications to geothermo-barometry. Amer. Mineral., 69:88-97.

Gastal, M.C.P. \& Nardi, L.V.S. 1995. A diversidade dos processos de diferenciação nos sistemas magmáticos alta sílica: Granito Jaguari e Complexo Granítico São Sepé, RS. In: SBGq, Congr. Bras. Geoq., 5, Niterói, Anais, pp. 220-223.

Hartmann L.A. \& Nardi L.V.S. 1983. Contribuição à geologia da região Oeste do Escudo Sul-Riograndense. In: SBG, Simp. Sul-Brasil. Geol., 1, Porto Alegre, Atas, 9-18.

Hartmann L.A., Porcher C.C., Remus M.V.D. 2000. Evolução das Rochas Metamórficas do Rio Grande do Sul. In: M. Holz, \& L.F.
De Ros (eds.) Geologia do Rio Grande do Sul. CIGO-UFRGS, Porto Alegre, pp: 79-118.

Koppe J., Hartmann L.A., Lisboa P.F.C., Monteiro R.N. 1985. Aspetos geológicos e estratigráficos do Complexo Bossoroca, São Sepé, Rio Grande do Sul. In: SBG, Simp. Sul-Brasil. Gol., 2, Anais, Florianópolis, pp. 32-36.

Mattos I.C. 1997. Estudo da Alteração Hidrotermal na Porção Sudoeste do Complexo Granítico São Sepé (São Sepé, RS). Dissertação de Mestrado, Instituto de Geociências, Universidade Federal do Rio Grande do Sul, 158p.

Porcher C.A., Leites S.R., Ramgrab G.E., Camozzato, E. 1991. Folha Passo do Salsinho/RS. Brasília, CPRM-DNPM, 235p.

Remus M.V.D., Hartmann L.A., McNaughton N.J., Groves D.I., Reischl J.L. 2000. Distal magmatic-hidrotermal origin for the Camaquã $\mathrm{Cu}$ (Au-Ag) and Santa Maria Pb, $\mathrm{Zn}(\mathrm{Cu}-\mathrm{Ag})$ Deposits. Gondw. Res., 3:155-174.

Santos E.L., Ramgrab G.E., Maciel L.A., Mosmann R. 1989. Mapa Geológico do Estado do Rio Grande do Sul. Porto Alegre, DNPM, mapa.

Sartori P.L.P. 1978. Petrologia do Complexo Granítico São Sepé, RS. 
Modelo Evolucional dos Granitos do Sul do Brasil. Tese de Doutorado, Instituto de Geociências, Universidade de São Paulo, São Paulo, 196p.

Spear F. \& Kohn M.J. 1990. Program Thermobarometry (version 1.9), In: F. Spear, Computer Exercise for P/T Path Calculation. New York, 126p.

Turner F. 1980. Metamorphic Petrology. McGraw-Hill, New York, $524 \mathrm{p}$.

Mottin C.C., Scandolara J.E., Novaes L.E.S.M. 1982. Geologia da Faixa I, Projeto Folha Passo do Salsinho. Trabalho de Graduação, Instituto de Geociências, Universidade Federal do Rio Grande do Sul, 257p.

Yardley B.W.D. 1989. An introduction to Metamorphic Petrology.
Longman Scientific \& Technical, Essex, 247p.

Zarpelon P.R. 1986. Geologia Estrutural, Estratigrafia e Petrologia de uma parte do Greenstone Belt Cerrito do Ouro, Município de São Sepé/RS. Dissertação de Mestrado, Instituto de Geociências, Universidade Federal do Rio Grande do Sul, 203p.

Wildner W. 1990. Caracterização Geológica e Geoquímica das Seqüências Ultramáfica e Vulcano-Sedimentares da Região da Bossoroca, RS. Dissertação de Mestrado, Instituto de Geociências, Universidade Federal do Rio Grande do Sul, 215p.

Manuscrito A-1258

Recebido em 02 de outubro de 2001

Revisão dos autores em 10 de novembro de 2003 Revisão aceita em 20 de novembro de 2003 